lecture of the session and a commemoration service, as well as a series of gatherings for athletic and social activities. The College was founded by men of great vision and faith whose first meetings were held in London in 1869 in Mitre Court and in the Freemasons' Tavern off Fleet Street. They decided to launch a scheme for the foundation of the University of Wales, and in October 1892 the present College at Aberystwyth was opened in a building designed as a hotel and beautifully situated on the shores of Cardigan Bay. Under the principalship of the Rev. Thomas Charles Edwards, twenty-five men students took arts courses ; to-day there are more than 1,100 men and women in the College, drawn from all parts of England, Wales and overseas, reading science, arts, music, law and rural science. The hotel buildings have long since proved inadequate, and with the help of many private donors, the College now owns a site totalling about 400 acres, including the Welsh Plant Breeding Station, and adjacent to the National Library of Wales.

The large and distinguished gathering of old students who returned for the seventy-fifth anniversary is a testimony to the widespread influence of their alma mater, and there can have been few occasions when one building held such a constellation of principals and vice-chancellors as that which gathered on October 25 for the presentation of degrees, honoris causa. The graduands included Sir James Irvine, principal and vice-chancellor of the University of St. Andrews, and Sir Hector Hethering. ton, principal and vice-chancellor of the University of Glasgow, both of whom delivered addresses during the celebrations. On October 26, the commemoration service concluded with a requiem for members of the College who gave their lives in the Great War. The music, written for the occasion by the present principal and the professor of music, was sung by the College choir.

\section{Association of British Science Writers}

Tнस Association of British Science Writers was formed on March 3. Its aims are to explain science to the general public ; to further the special interests of science writers; to afford the necessary protection when required; to enable science writers to act as a body ; to provide facilities, as desired by the members, for genoral meetings with useful persons possessing material or knowledge of general interest to the Association, or whose interest in the Association is beneficial to its aims and interests; to act, perform or prosecute any other activities from time to time, as and when considered necessary by the members or appointed committee. Membership is open to journalists in the United Kingdom who are bona fide science writers, that is, those who write about science through the media of the Press, dailies and weeklies, journals, magazines and books, etc., and who earn the major part of their income from science writing. The chairman is Mr. J. G. Crowther, science correspondent of the Manchester Guardian; and Mr. Maurice Goldsmith, science editor of Reynolds News, is the honorary secretary and treasurer. Sir Richard Gregory is the first honorary member of the Association because of the great work he has done in popularizing science. The Association also aims at setting up an associate membership to include those scientists who write regularly about science, but who do not earn the major part of their income from this activity.

\section{Research on Toxicology}

THe following have been appointed by the Medical Research Council to serve on a new committee to advise and assist in the promotion of research in toxicology, with particular reference to industrial hazards : Prof. G. R. Cameron (chairman), Prof. J. H. Gaddum, Dr. Donald Hunter, Dr. F. C. MacIntosh, Dr. E. R. A. Merewether, Prof. R. A. Peters, J. Davidson Pratt, Dr. J. R. Squire, Dr. J. Walker and Dr. J. M. Barnes (secretary).

For carrying out experimental work within the field covered by the Committee, the Council has recently established at the Chemical Defence Experimental Station at Porton (Wilts), by arrangement with the Ministry of Supply, a new Toxicology Research Unit under the direction of Dr. J. M. Barnes. For clinical investigations in this field the Council already has a Department for Research in Industrial Medicine at the London Hospital, under the direction of Dr. Donald Hunter, and an Industrial Medicine Research Unit at the Birmingham Accident Hospital, under the direction of Dr. J. R. Squire. In appropriate circumstances, research in the subject may be promoted by the Council elsewhere, either within its own staff organisation or by means of grants to independent workers.

\section{Soil Surveys in the Caribbean}

Ат the second session of the West Indies Conference, which met in St. Thomas, Virgin Islands of the United States, in February-March 1946, the question of soil surveys in the Caribbean was considered. With the object of obtaining advice on the recommendation, the Caribbean Commission, of which the West Indies Conference is an auxiliary body, appointed a sub-committee of soil scientists representative of French, Netherlands, British and Uniter States territories of the Caribbean and comprising Dr. H. J. Page, principal of the Imperial College of Tropical Agriculture, Trinidad (chairman); Mr. D. Blanche, acting head of the Agricultural Service, Martinique; Dr. J. A. Bonnet, head of the Soils Department, Agricultural Experiment Station of the University of Puerto Rico ; Prof. F. Hardy, professor of chemistry and soil science, Imperial College of Tropical Agriculture, Trinidad; Dr. H. J. Mïller, agricultural chemist, Department of Agricultural Eeonomics, Surinam.

The sub-committee recommended that a Conference of Soil Scientists should be held in Puerto Rico in 1948, under the auspices of the Committee on Agriculture, Nutrition, Fisheries and Forestry of the Caribbean Research Council, for the purpose of studying systems and methods of classification and mapping of tropical soils, with special reference to the standardization of such systems and methods for use in soil surveys throughout the Caribbean region, and to carrying out such surveys as soon as possible. The proposed agenda is : (i) Presentation and discussion of collected data on soil-forming factors of the various territories. (ii) Standardization of field and laboratory methods of soil surveys. (iii) Discussion of different systems of soil classification and mapping. (iv) Formulation of a detailed regional programme of soil surveys. (v) Survey of problems of soil erosion, soil conservation and soil renovation in the different territories. (vi) Practical application of soil surveys to land utilization. It was recommended that attendance at the conference should be as representative as possible, and should include soil 
scientists who are specially interested in tropical soils from the above-mentioned points of view, not only from the Caribbean, but also from other countries; special reference was made to Cuba, Haiti and the Dominican Republic, and it was recommended that the Governments of these countries should be invited to send representatives to participate in the conference. The recommendations have been approved by the Caribbean Commission, and a working committee has been set up to prepare for the conference, the date of which has not yet been definitely fixed.

\section{The Giant Panda}

IT has been announced by the Chinese Government that the Szechwan Frovincial Government has limited the catching of pandas to one pair every five years. This regulation was made at the request of the Academia Sinica with the view of protecting this rare species from extinction. Few mammals have caused more scientific and lay interest than the giant panda (Ailuropoda melanoleuca, David), first made known to science when David sent skins home to France from his travels in western China during 1868-69. Several expeditions attempted to secure live specimens, and in 1937 one was exhibited by the New York Zoological Society, and in the following year another was shown in London. Their similarity to the true bears is not borne out by the skull, which resembles the raccoons, and thus the sub-family Ailurinæ of the raccoons (Procyonidæ) was created for the giant panda and the more numerous lesser panda (Ailurus fulgens). It is to be hoped that the lead by the Chinese Government will encourage other Eastern States to eurb the activities of collectors, who are likely to exterminate animals of limited distribution.

\section{Education and Training of Laboratory Technicians}

A Committee on the Education and Training of Laboratory Technicians was set up by a conference convened in 1946 by the Association of Scientifie Workers, the Association of University Teachers and the British Association of Chemists. Among the bodies now represented on it are the Institute of Physics, the Royal Institute of Chemistry, the Biological Council, the Institute of Medical Laboratory Technology and the Science Masters' Association, in addition to the three Associations that convened the conference; there are also representatives of industry and a number of senjor laboratory technicians on the Committee; representatives of other organisations concerned with the problem, including the Ministry of Education, are being coopted. The chairman of the Committee is Prof. F. R. Winton and the honorary secretary is now Dr. H. J.T. Ellingham (secretary, Royal Institute of Chemistry). The attention of the Committee has been directed essentially to that important class of technicians, which includes laboratory stewards and, at the highest level, laboratory superintendents, whose work is vital to the maintenance and operation of research laboratories in industrial organisations, research associations and academic institutions and of laboratories for the instruction of students in universities, technical colleges and schools. Their work involves experience of techniques derived from a number of branches of science and technology; most of them are to be regarded not-as potential chemists, physicists, biologists, otc., but as potential first-class laboratory technicians. So far, however, few courses have been provided for the training of technicians of this type, nor is there any qualification in their own field to which they may aspire. The Committee is therefore engaged in preparing syllabuses for the certificate and diploma stages of a general course of training for such laboratory technicians, based on proposals put forward by a sub-committee consisting of the laboratory technician members of the Committee. It is hoped to start a trial course early in 1948. In the meantime, it is understood that a representative group of laboratory technicians who have been associated with the work of the Committee are taking steps to constitute a professional qualifying body similar in many respects to the Institute of Medical Laboratory Technology.

\section{Thermo-nuclear Reactions under Terrestrial Con- ditions}

The possibility of initiating thermo-nuclear re. actions under terrestrial conditions is discussed by Dr. J. H. J. Poole (Proc. Roy. Dublin Soc., 24, 71; 1946). It is pointed out that the results obtained by Atkinson, Gamow and Teller, Bethe and others, in their investigations of thermo-nuclear reactions as applied to stellar conditions, are equally valid for terrestrial conditions. In applying these results to the sea, which is the largest known source of thermonuclear energy on the earth, four types of reactions need to be considered. They are proton-proton, proton-deuteron, and two forms of deuteron-deuteron reaction. The deuteron-deuteron reaction is shown to be the most important, by comparing the values of the rate of generation of thermo-nuclear energy derived for the several reactions. The question whether it is possible to initiate and maintain a thermo-nuclear reaction in the sea is discussed by considering the case of a sphere of water in which thermo-nuclear energy is being generated and which is radiating as a black-body. It is shown that the minimum radius of such a sphere must be of the order of $3 \times 10^{6} \mathrm{~km}$., so that there would seem to be very little danger of starting a world-wide explosion by dropping an atom bomb into the sea. (Dr. Poole's paper was written prior to the Bikini atom bomb tests.) If the sphere consisted entirely of heavy water, the minimum radius is reduced to $3.6 \mathrm{~km}$., so that even in this extreme case a selfmaintained thermo-nuclear explosion would be unlikely to be started by an atom bomb. It is probable, however, that if heavy water were incorporated in the bomb, with some of the energy liberated in the explosion being derived from deuteron reactions, more complete fission of the active heavy-element constituent would be ensured by the neutrons emitted by the reaction.

\section{Catalogue of Laboratory Equipment}

IN the days before the War, the comprehensive catalogues of the laboratory furnishing firms were the 'bibles' of all those concerned with the ordering and purchasing of laboratory apparatus and instruments. The long years of abnormal circumstances and particularly of paper shortages have deprived laboratory workers of these ready and compact sources of information covering the whole range of scientific laboratory equipment. It is therefore heartening as a foretaste of more normal conditions that Messrs. Griffin and Tatlock, Ltd., have been able to issue a new and very substantial catalogue of scientific apparatus, and that the familiar, but out-of- 